\title{
Global transport of light elements boron and carbon in the full-W ASDEX
}

\section{Upgrade}

\author{
A. Hakola ${ }^{\mathrm{a} *}$, J. Likonen ${ }^{\mathrm{a}}$, S. Koivuranta ${ }^{\mathrm{a}}$, K. Krieger ${ }^{\mathrm{b}}$, M. Mayer $^{\mathrm{b}}$, R. Neu ${ }^{\mathrm{b}}$, V. Rohde ${ }^{\mathrm{b}}$, \\ K. Sugiyama ${ }^{b}$, ASDEX Upgrade Team \\ ${ }^{a}$ VTT, Association EURATOM-Tekes, P.O. Box 1000, FI-02044 VTT, Finland \\ ${ }^{b}$ Max-Planck-Institut für Plasmaphysik, EURATOM Association, Boltzmannstr. 2, 85748 Garching, \\ Germany
}

\begin{abstract}
Transport of carbon and boron has been investigated in the full-W ASDEX Upgrade after experimental campaigns with (2008) and without (2007) boronizations. For this purpose, poloidal deposition profiles of the two elements on tungsten and graphite regions of lowerdivertor tiles have been determined. Carbon is mainly deposited in the inner divertor - 8090\% of the determined ${ }^{12} \mathrm{C}$ and ${ }^{13} \mathrm{C}$ inventories on $\mathrm{W}$ - while boron shows a much more symmetric deposition profile. In the unboronized machine, the boron inventories are a factor of 10 smaller than in the boronized case and result from residual boron atoms left in the torus prior to the 2007 campaign. Both carbon and boron are deposited more efficiently and/or show less erosion on graphite than on tungsten, particularly in the outer divertor. For ${ }^{13} \mathrm{C}$, the difference is $10-100$ in favor of graphite. This is most probably caused by a higher re-erosion from tungsten surfaces.
\end{abstract}

JNM Keywords: First wall materials, Carbon, Surface Effects, Tungsten PSI-19 keywords: ASDEX-Upgrade, Boronization, Carbon impurities, Erosion \& Deposition, Surface analysis PACS: 52.40.Hf, 52.55.Fa, 52.55.Rk, 68.49.Sf 
Corresponding author address: VTT Materials for Power Engineering, P. O. Box 1000, FI-

02044 VTT, Finland

Corresponding author e-mail: ahhakola@gmail.com

Presenting author: Dr. Antti Hakola

Presenting authore-mail: ahhakola@gmail.com

\section{Introduction}

Erosion, deposition, and transport of eroded material are key issues in tokamak research, particularly from the viewpoint of ITER and its successors. These topics are linked to the critical safety and design aspects of fusion reactors including the lifetime of their plasma-facing components (PFC), production of dust, and accumulation of tritium in the PFCs $[1,2]$.

This paper focuses on the deposition of the light elements carbon and boron in ASDEX Upgrade during the 2007 and 2008 experimental campaigns. Since 2007, ASDEX Upgrade has operated with an all-tungsten first wall [3,4], and carbon has thus been present as a trace impurity. In addition, tracer-injection experiments with ${ }^{13} \mathrm{C}$ have given dedicated information on the migration of carbon and the effect of substrate on its final deposition [5]. Considering boron, the 2007 and 2008 campaigns have enabled investigating its deposition behavior in different environments. In 2007, ASDEX Upgrade was operated without boronizations whereas in 2008 the plasma operations were carried out in a regularly boronized machine [6].

We have studied the deposition of $\mathrm{B},{ }^{12} \mathrm{C}$, and ${ }^{13} \mathrm{C}$ on the lower-divertor regions of ASDEX Upgrade by analyzing a set of tiles after both the 2007 and 2008 campaigns. Secondary ion mass spectrometry (SIMS), Rutherford backscattering (RBS), and nuclear reaction analysis (NRA) were used for this purpose. Main emphasis was put on tungsten as 
the plasma-facing material but in the case of boron in 2008 and ${ }^{13} \mathrm{C}$ in 2007 , also uncoated graphite areas of special marker tiles were investigated.

\section{Experimental}

\subsection{Plasma operations in 2007 and 2008}

During the 2007 and 2008 experimental campaigns, ASDEX Upgrade was operated with a full-W first wall. The 2007 campaign consisted of 605 plasma discharges with a total divertor time of 2620 s. In 2008, the corresponding number of discharges was 726 with a divertor time of 3530 s before an unscheduled maintenance break; the 2008 tiles were removed from the torus during that break. In 2007, no boronizations were performed and the wall tiles were carefully cleaned from previous deposition remnants. In 2008, altogether 3 boronizations with $\mathrm{B}_{2} \mathrm{D}_{6}$ were carried out before the maintenance break. In each boronization, approximately $3.4 \times 10^{23}$ boron atoms were injected into the torus, and from residual gas analysis a deposition efficiency of $97 \%$ has been determined [7].

In the end of the 2007 campaign, also a ${ }^{13} \mathrm{C}$ injection experiment was carried out. This consisted of puffing isotopically labeled methane $\left({ }^{13} \mathrm{CH}_{4}\right)$ into the torus during 12 identical plasma discharges (in total $2.7 \times 10^{22}$ atoms of ${ }^{13} \mathrm{C}$ ) in L-mode in deuterium and with a lower single-null configuration (discharges \#22573-22585). The puffing was performed from one toroidal location at the outer midplane, some $45^{\circ}$ off the poloidal location where the surface analyses were made. Details of the experiment and a discussion on the toroidal symmetry of the ${ }^{13} \mathrm{C}$ injection can be found in Ref. [5].

\subsection{Analysis of wall tiles}

The following tiles were analyzed for their surface densities of carbon and boron:

- A full set of standard W-coated lower-divertor tiles from one poloidal cross section after the 2007 campaign. Also selected main-chamber tiles from the same cross section were investigated. Both the deposition of ${ }^{13} \mathrm{C}$ and the amounts of ${ }^{12} \mathrm{C}$ and $\mathrm{B}$ on 
tungsten were determined. This article concentrates on the results from the lowerdivertor tiles.

- A complete set of lower-divertor marker tiles, removed after the 2007 campaign from a cross section adjacent to the analyzed standard tiles. Uncoated poloidal graphite areas of these tiles were studied to obtain the ${ }^{13} \mathrm{C}$ deposition profile on carbon.

- Marker tiles from the inner- and outer-divertor regions after the first half of the 2008 campaign. The deposition of ${ }^{12} \mathrm{C}$ on the $\mathrm{W}$-covered regions and the accumulation of $\mathrm{B}$ on both graphite and $\mathrm{W}$ areas of the tiles were at the focus of the research.

All the tiles had graphite as their substrate material. The standard tiles had been coated with a 3-4- $\mu$ m thick W film, produced using physical vapor deposition (PVD), except for the outer strike-point tile which had a 200- $\mu \mathrm{m}$ thick vacuum-plasma-spraying (VPS) coating of tungsten. The marker tiles consisted of poloidal and toroidal regions with different coatings on them. All these coatings have been produced by DIARC-Technology Inc. The regions relevant for this article are as follows: (i) an uncoated poloidal stripe at the center of every marker tile, (ii) a 200-nm thick W coating on the remaining areas of each inner-divertor (and roof-baffle) tile, (iii) 500-nm thick poloidal $\mathrm{W}$ stripes on the outer divertor tiles, and (iv) a $1.5-\mu \mathrm{m}$ thick $\mathrm{W}$ coating on the outer strike-point tile. The poloidal locations of the tiles, retrieved for surface analyses both in 2007 and 2008, are shown in Fig. 1.

In this work, the analyses were made using SIMS, NRA, and RBS. The SIMS measurements were made with a double focussing magnetic sector instrument (VG Ionex IX70S). Depth profiles of boron $\left({ }^{10} \mathrm{~B}\right)$, carbon isotopes ${ }^{12} \mathrm{C}$ and ${ }^{13} \mathrm{C}$, and tungsten $\left({ }^{184} \mathrm{~W}\right)$ on the samples were measured. The less common isotope of natural boron $\left({ }^{10} \mathrm{~B}\right)$ was selected for SIMS profiling in order not to saturate the detector. A 5-keV $\mathrm{O}_{2}{ }^{+}$primary ion beam was used and the current of the primary ions was adjusted to $500 \mathrm{nA}$. The beam was raster-scanned across an area of $300 \times 430 \mu \mathrm{m}^{2}$. A 10-\% electronic gate and a 1-mm optical gate were used 
in all the measurements. The mass resolution was typically $\mathrm{m} / \Delta \mathrm{m}=300 \mathrm{at} \mathrm{m} / \mathrm{z}=28$ but in the ${ }^{13} \mathrm{C}$ analyses a higher resolution of 2000 was used to distinguish ${ }^{13} \mathrm{C}$ from other isobars such as ${ }^{12} \mathrm{CH}^{+}$.

The composition of the analyzed layers was determined by integrating the intensity of each mass signal down to a depth where the background level with respect to the tungsten signal from the coating or the ${ }^{12} \mathrm{C}$ signal from the substrate was reached. For all the samples, the largest contributions came from a 100—500-nm thick surface layer. In each selected poloidal location the measurements were repeated $2-3$ times and the extracted results were averaged over.

The RBS analyses were carried out using 3-MeV protons at a backscattering angle of $165^{\circ}$ [8]. NRA was done using 2.5-MeV ${ }^{3} \mathrm{He}^{+}$ions, utilizing the ${ }^{12} \mathrm{C}\left({ }^{3} \mathrm{He}, \mathrm{p}\right){ }^{14} \mathrm{~N}$ and ${ }^{11} \mathrm{~B}\left({ }^{3} \mathrm{He}, \mathrm{p}\right){ }^{13} \mathrm{C}$ reactions at $150^{\circ}$. The diameter of the ion beam in both NRA and RBS was $\sim 1.8 \mathrm{~mm}$. The amount of all boron $\left({ }^{10} \mathrm{~B}+{ }^{11} \mathrm{~B}\right)$ on the tiles was obtained by dividing the calculated surface densities for ${ }^{11} \mathrm{~B}$ by its natural abundance of $80.2 \%$.

The NRA and RBS measurements provided quantitative data on the deposition of ${ }^{12} \mathrm{C}$ and B on W (and on graphite), and they were used to convert SIMS results to atoms $/ \mathrm{cm}^{2}$. For ${ }^{13} \mathrm{C}$, calibration samples with well-known surface densities of ${ }^{13} \mathrm{C}$ on $\mathrm{W}$ and on $\mathrm{C}$ were utilized in the conversion.

\section{Results}

\subsection{Deposition of carbon on tungsten and graphite}

In the full-W ASDEX Upgrade, carbon is deposited predominantly in the inner divertor with peaks in the private flux region below the inner strike point and on the innermost tiles 6A and 6B. This can be observed in Fig. 2 where the SIMS results of the deposition of ${ }^{12} \mathrm{C}$ on tungsten in the lower divertor as a function of the poloidal $s$ coordinate (see Fig. 1 for definition) are shown, both for the 2007 campaign (part (a)) and for the first 
phase of the 2008 campaign (part (b)). In addition, the figure shows distributions for the inner and outer strike points during each campaign.

Although both the curves in Fig. 2 show the same overall tendency for the deposition behavior of carbon, there are also differences. The order-of-magnitude higher carbon amounts in tiles 6A, 6B, and 5 after the 2008 campaign can be explained by arcing. Arcing erodes the W coatings and results in additional deposition next to the arc tracks [9]. The samples analyzed in 2007 were taken from a location where little erosion by arcs was observed while the 2008 coatings were more damaged and hence the extra deposition of carbon was significant. Another observation is that in the boronized case in 2008 the deposited layers below both the inner and outer strike points are much thicker than in 2007.

By assuming toroidally symmetric deposition, we performed poloidal and toroidal integration over the investigated divertor regions and obtained that $1.6 \times 10^{23}$ atoms of ${ }^{12} \mathrm{C}$ had been accumulated in the inner and outer divertors in 2008. This corresponds to a carbon inventory of $\sim 3 \mathrm{~g}$, of which more than $80 \%$ was found in the inner divertor. In 2007 , the corresponding values for the whole divertor were $7.0 \times 10^{22}$ atoms and $\sim 1.5 \mathrm{~g}$. This estimate is well in line with the published results from the 2007 campaign [10].

The ${ }^{12} \mathrm{C}$ observations presented above are supported by the measurements of the deposition of ${ }^{13} \mathrm{C}$ on both $\mathrm{W}$ and graphite after the 2007 injection experiment (see Fig. 3). As particularly the ${ }^{13} \mathrm{C}$ on $\mathrm{W}$ curve in Fig. 3 shows, ${ }^{13} \mathrm{C}$ exhibits an asymmetric deposition pattern with peaks in the inner private-flux region and the determined surface densities of ${ }^{13} \mathrm{C}$ on $\mathrm{W}$ being locally one or two orders of magnitude higher in the inner than in the outer divertor. Even more interesting is that the deposition depends largely on the substrate material: in the case of graphite, the distribution is much more symmetric between the inner and outer divertors. We attribute the difference to a larger erosion of carbon atoms from $\mathrm{W}$, especially in the outer divertor: this is a net erosion area for carbon, so deposited films are inherently 
rather thin $[5,8]$. In the inner divertor, the deposited layers are thicker and the substrate effect does not play such a large role.

In total, some $9 \%$ of the injected ${ }^{13} \mathrm{C}$ was experimentally found deposited in the torus, with the lower divertor containing one tenth of this. The sinks for the missing carbon will be the subject of forthcoming injection experiments in ASDEX Upgrade, but our results already indicate that most of the injected carbon is deposited in the main chamber as evidenced by simulations with the DIVIMP code [5].

\subsection{Deposition of boron in 2007 and 2008}

The poloidal deposition profile of boron on tungsten is significantly different after boronized and unboronized plasma operations. In the boronized case, boron is observed to accumulate in the same regions where the thickest carbon deposits are found: below the inner and outer strike points and on tiles 6A and 6B. This can be noticed in Fig. 4(a) where both the SIMS and two different NRA profiles, measured from the $\mathrm{W}$ areas of the 2008 marker tiles, are shown; the NRA measurement points were located on both sides of the graphite marker stripe. The inward/outward asymmetry in deposition is not so remarkable as in the case of carbon. In the outer divertor, the $\mathrm{B}$ content on the $\mathrm{W}$ coatings even increases to levels comparable to those measured from the inner-divertor tiles. In addition, the three curves in Fig. 4(a) show large scattering in the inner-divertor zone most heavily affected by arcing. Similarly to the case of carbon, the deposition was enhanced in these areas. SIMS tends to somewhat overestimate the highest surface densities for boron, which explains the large discrepancies between NRA and SIMS results in tiles 3B and 5.

Considering the unboronized campaign in 2007, the determined surface densities for boron on $\mathrm{W}$ result from residual $\mathrm{B}$ atoms in the torus and are typically 2-10 times smaller than what was obtained for the 2008 tiles (see Fig. 4(b)). In the outer divertor, the evaluated boron concentrations stay in a rather steady level while in the inner divertor the deposition is peaked 
in the arcing tiles 6A and 6B and in tiles 4 and 9C. Compared to the 2008 results, the outer divertor appears now to be responsible for the largest boron inventories due to its larger surface area.

Again by assuming toroidally symmetric deposition, the number of boron atoms measured in the inner divertor in 2008 is $1.3-4.4 \times 10^{22}$ depending on which of the three data sets in Fig. 4(a) is used. On average, approximately 3\% of the injected boron atoms $\left(\sim 1.0 \times 10^{24}\right)$ have ended up in this region. The corresponding numbers for the outer divertor range from $2.0 \times 10^{22}$ to $3.0 \times 10^{22}$ atoms. Altogether a deposition efficiency of $5-6 \%$ is obtained with the inner and outer divertor being equally dominant sinks. One should note that the boron atoms injected into the vessel during boronizations are deposited mainly in the main chamber [7], from which they are eroded and deposited in the divertor regions during plasma operations. Under unboronized conditions, the inner divertor and roof baffle contain 6.6$6.8 \times 10^{21}$ boron atoms and approximately $6.8-11 \times 10^{21}$ atoms have found their way into the outer divertor.

Similarly to the deposition of ${ }^{13} \mathrm{C}$ on $\mathrm{W}$ and graphite, also $\mathrm{B}$ is deposited differently on different substrate materials as one observes from Fig. 5. This figure presents poloidal deposition profiles of B on graphite stripes of the 2008 marker tiles, both the SIMS and RBS results. In addition, the NRA and SIMS data sets of B on W from Fig. 4(a) have been reproduced in the figure. The surface densities for B on C are larger than the corresponding values on tungsten, particularly on tile 4 and at the outer divertor where the difference is some 2-10 in favor of the graphite regions. Based on the values in Fig. 5, the total deposition of B in the inner and outer divertors of a carbon machine would be $1.4 \times 10^{23}$ and $5.3 \times 10^{22}$ atoms, respectively, in total $\sim 19 \%$ of the injected boron atoms. This factor is an upper limit but it demonstrates that boron is more readily deposited - or less eroded - on C than on W. The inner divertor value corresponds to $2.5 \mathrm{~g}$, and agrees with the results obtained from carbon- 
dominated phases of ASDEX Upgrade in 2002-2006: from $2.3 \mathrm{~g}$ to $4.8 \mathrm{~g}$ in $3000 \mathrm{~s}$ of plasma time and with 5-6 boronizations per campaign [6].

\section{Conclusions}

We have investigated transport and subsequent deposition of carbon and boron in the lower-divertor regions of the full-W ASDEX Upgrade after experimental campaigns with unboronized (in 2007) and boronized (in 2008) plasma operations. Poloidal deposition profiles of the two elements were determined on tungsten and on graphite to study also the effect of the substrate material on the deposition efficiency. Carbon was observed to be deposited mainly in the inner divertor: $80-90 \%$ of the measured amounts of ${ }^{12} \mathrm{C}$ and ${ }^{13} \mathrm{C}$ on $\mathrm{W}$ were found in these regions. In contrast, boron showed a much more symmetric deposition profile. In the boronized machine, on average $55 \%$ and $45 \%$ of the deposited boron atoms were found in the inner and outer divertor regions, respectively. In the unboronized machine, the corresponding percentages were $45 \%$ for the inner divertor and roof baffle and $55 \%$ for

the outer divertor. Furthermore, we observed a clear substrate effect for both carbon and boron: the surface densities of both the elements were larger on graphite than on tungsten, particularly in the outer divertor. For carbon $\left({ }^{13} \mathrm{C}\right)$, this difference was some $10-100$, whereas for boron only $2-10$ due to the campaign-integrated nature of the boron data. We attribute the substrate effect to a higher re-erosion from tungsten surfaces [5,11].

\section{Acknowledgments}

This work, supported by the European Communities under the contract of Association between Euratom and Tekes, was carried out within the framework of the Task Force on Plasma Wall Interactions of the European Fusion Development Agreement. The views and opinions expressed herein do not necessarily reflect those of the European Commission. The technical support by M. Fußeder and J. Dorner is gratefully acknowledged. 


\section{References}

[1] G. Federici, C. H. Skinner, J. N. Brooks, et al., Nucl. Fusion 41 (2001) 1967.

[2] J. Roth, E. Tsitrone, A. Loarte, et al., J. Nucl. Mater. 390-391 (2009) 1.

[3] R. Dux, V. Bobkov, A. Herrmann, et al., J. Nucl. Mater. 390-391 (2009) 858.

[4] R. Neu, V. Bobkov, R. Dux, et al., Phys. Scr. T138 (2009) 014038.

[5] A. Hakola, J. Likonen, L. Aho-Mantila, et al., Plasma Phys. Control. Fusion 52 (2010) 065006.

[6] A. Kallenbach, R. Dux, M. Mayer, et al., Nucl. Fusion 49 (2009) 045007.

[7] V. Rohde, R. Dux, A. Kallenbach, et al., J. Nucl. Mater. 363-365 (2007) 1369.

[8] M. Mayer, V. Rohde, G. Ramos, et al., Phys. Scr. T128 (2007) 106.

[9] A. Herrmann, M. Balden, M. Laux et al., J. Nucl. Mater. 390-391 (2009) 747.

[10] M. Mayer, V. Rohde, K. Sugiyama, et al., J. Nucl. Mater. 390-391 (2009) 538.

[11] H. Maier, K. Schmid, and W. Eckstein, J. Nucl. Mater. 337-339 (2005) 480. 


\section{Figure captions}

Figure 1. Poloidal cross section of the lower divertor of ASDEX Upgrade together with the definition for the $s$ coordinate. The tiles analyzed in 2008 are marked in the figure in dark gray.

Figure 2. Poloidal deposition profile of ${ }^{12} \mathrm{C}$ on tungsten (a) in 2007 and (b) in 2008, determined using SIMS. The histograms indicate the inner and outer strike-point distributions during the campaigns.

Figure 3. Poloidal deposition profile of ${ }^{13} \mathrm{C}$ on tungsten and on carbon in 2007 together with the strike-point distributions during the ${ }^{13} \mathrm{C}$ injection experiment.

Figure 4. Poloidal deposition profile of B on tungsten (a) in 2008 and (b) in 2007, determined from the NRA and SIMS results.

Figure 5. Poloidal deposition profile of B on graphite in 2008, determined from the RBS (red) and SIMS results (light red) together with the NRA (blue) and SIMS data (light blue) for B on W from Fig. 4(a). 


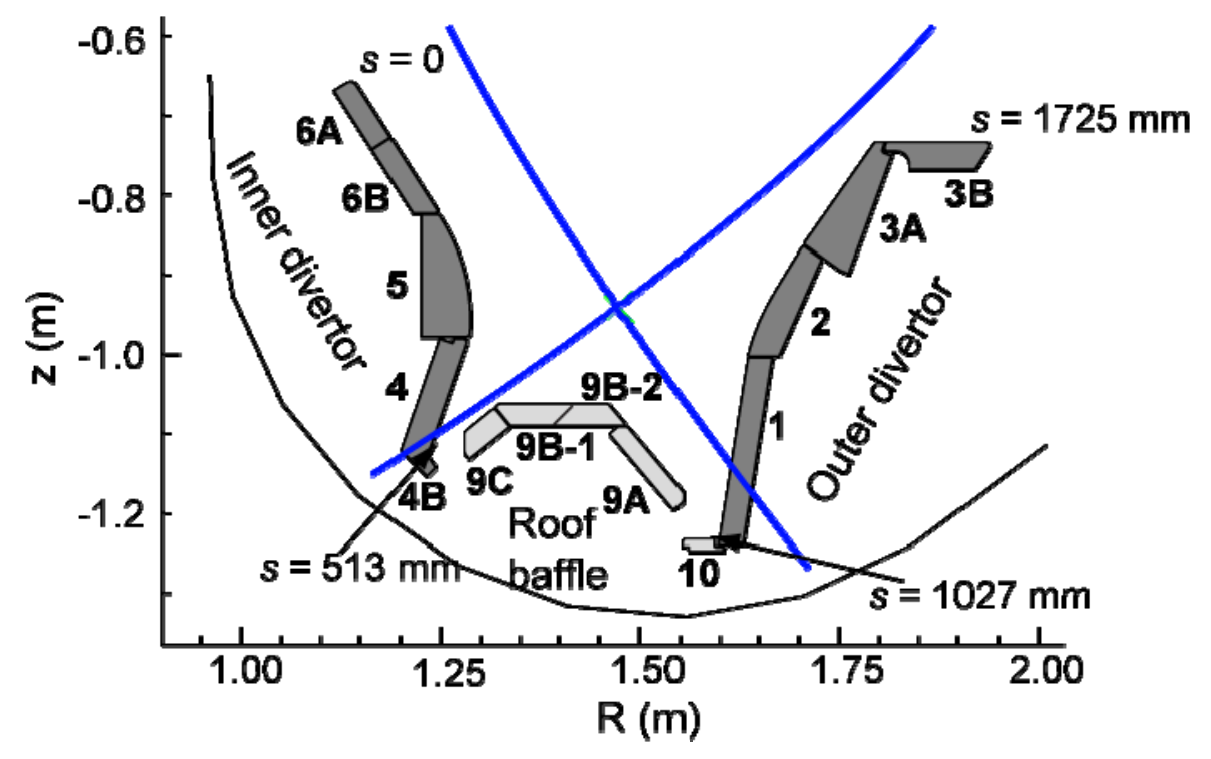

Figure 1. 


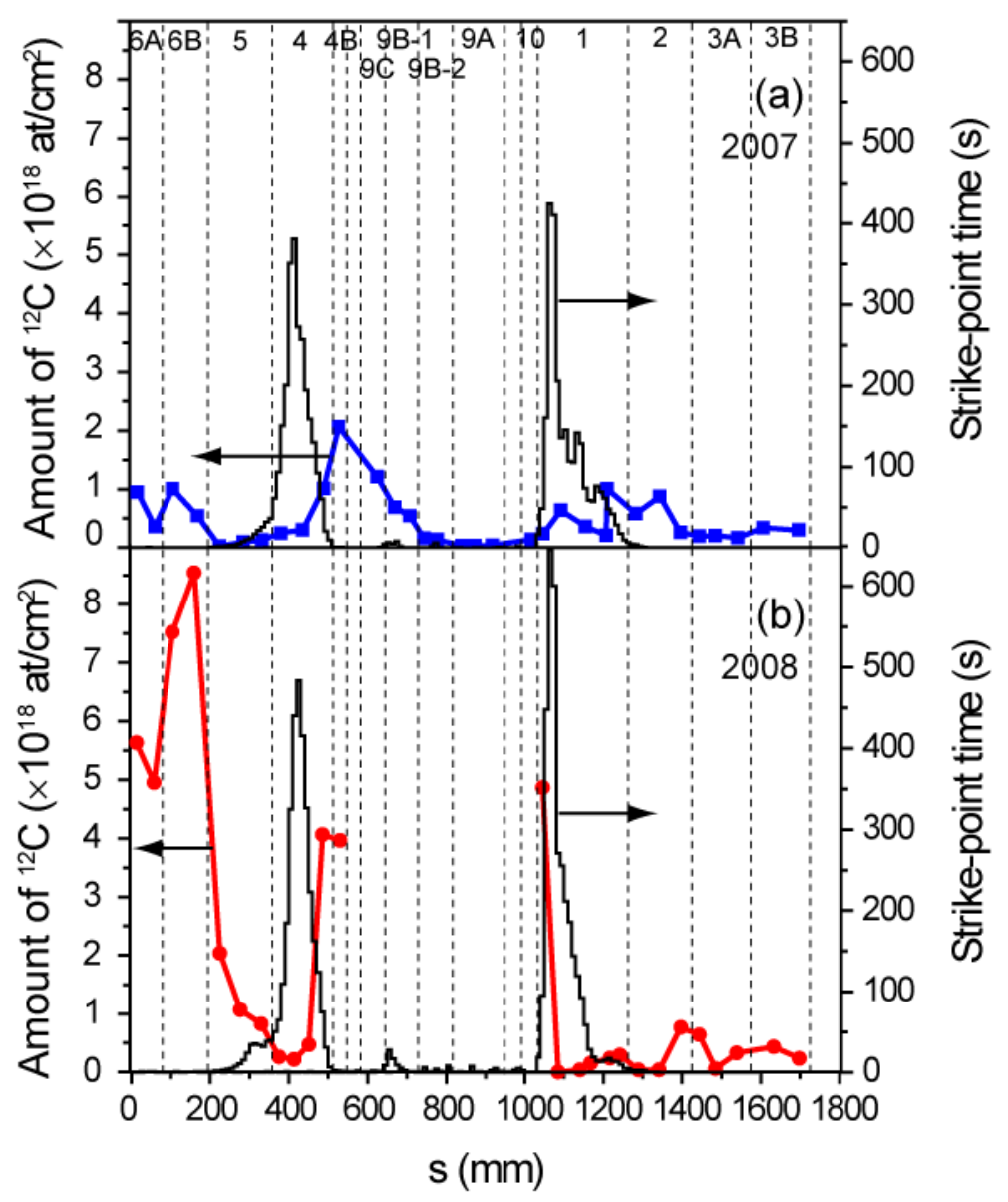

Figure 2. 


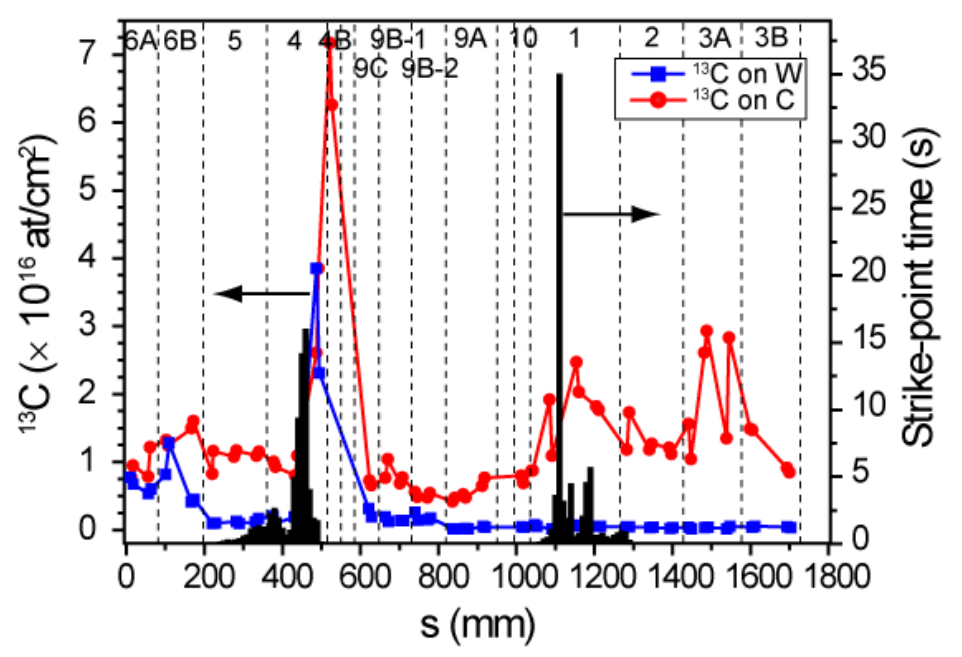

Figure 3. 


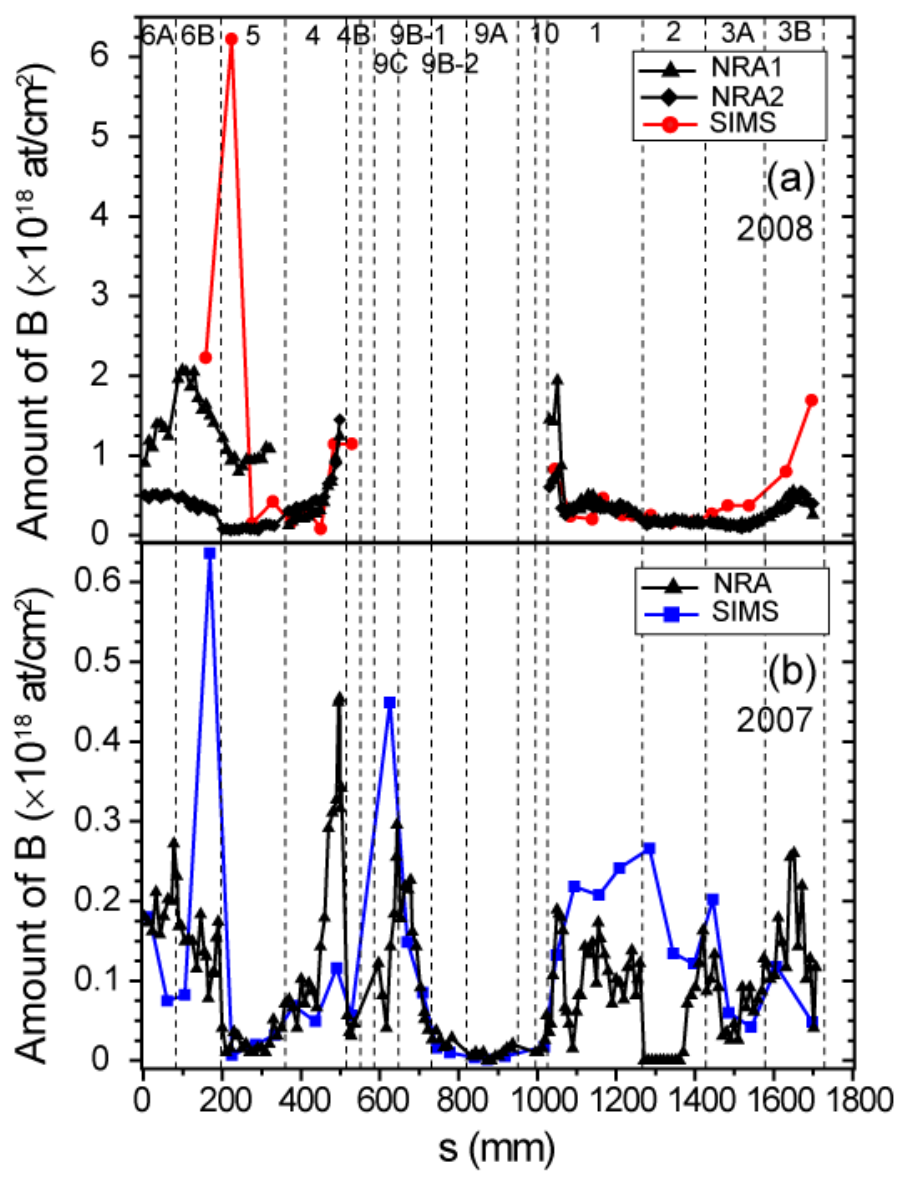

Figure 4. 


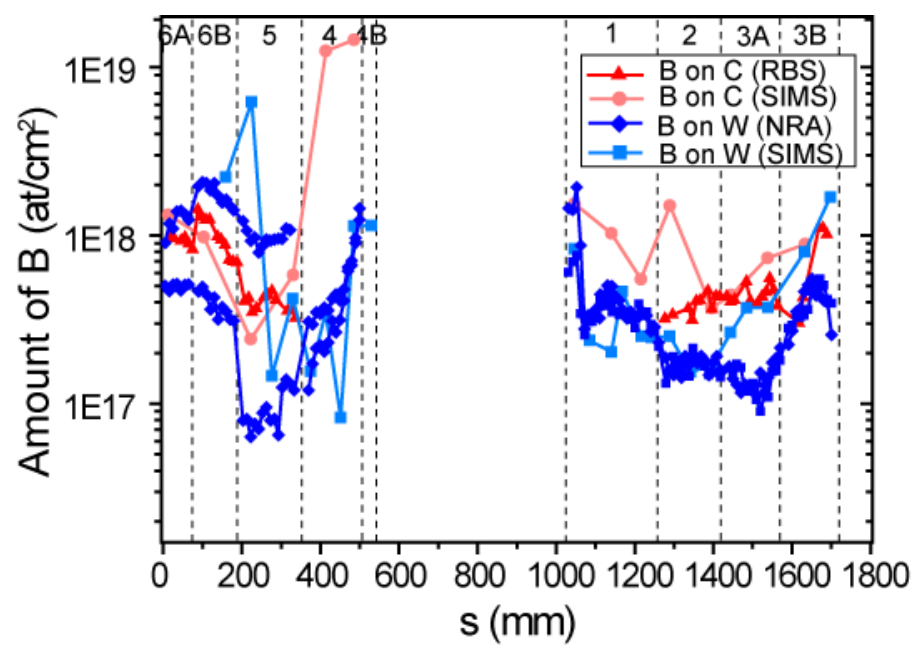

Figure 5. 